\title{
Biomarker responses to weaning stress in beef calves
}

\author{
Aran O'Loughlin a,b, Mark McGee c, Sean Doyle ${ }^{\mathrm{b}}$, Bernadette Earley ${ }^{\mathrm{a}, *}$ \\ a Animal and Bioscience Research Department, Animal E Grassland Research and Innovation Centre, Teagasc, Grange, Dunsany, Co. Meath, Ireland \\ ${ }^{\mathrm{b}}$ Department of Biology, National Institute for Cellular Biotechnology, National University of Ireland Maynooth, Co. Kildare, Ireland

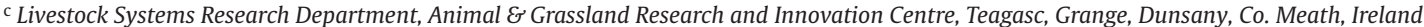

\section{A R T I C L E I N F O}

\section{Article history:}

Received 4 November 2013

Accepted 8 June 2014

\section{Keywords:}

Cattle

Weaning

Stress

Biomarkers

Haematology

Cortisol

CXCL8

\begin{abstract}
A B S T R A C T
The study objective was to investigate the physiological effects of weaning on beef calves and identify a panel of blood-based welfare biomarkers. On the day (d) of weaning (d 0), 16 spring-born, singlesuckled, beef bull calves that previously grazed with their dams at pasture, were assigned to one of two treatments: ( 1 ) control $(n=8)$, calves were loose-housed with their dam, (2) weaned $(n=8)$, calves were abruptly separated from their dam and loose-housed. Jugular blood was collected on d $-4,0,1,2,3,7$, and 14 relative to weaning ( $\mathrm{d} 0$ ) and assayed for inflammatory and steroid variables. Total leukocyte counts were measured in whole blood. It is concluded that neutrophil number is a robust biomarker of stress and that plasma CXCL8 is a sensitive indicator of stress in weaned and control calves. In future studies, these two biomarkers should be central to the characterisation of stress responses.
\end{abstract}

(C) 2014 Elsevier Ltd. All rights reserved.

\section{Introduction}

Weaning is a multifaceted stressor that usually involves numerous husbandry practices, including the abrupt separation of the beef calf from its dam, a nutritional adjustment to a non-milk diet and social reorganisation and, additionally, is often associated with housing (Enriquez et al., 2011; Lynch et al., 2010). Housing has been reported to alter the neutrophil and lymphocyte immunophenotype of calves, along with the acute phase response (Lynch et al., 2010), with a more pronounced stress response occurring in calves weaned at housing compared with those housed with their dams (Lynch et al., 2010, 2011). Alterations in calf immunity following weaning stress are of great importance as these changes are thought to be associated with increased incidence and severity of respiratory disease (Duff and Galyean, 2007).

Neutrophilia is one of the most frequently reported biomarkers of stress in cattle following weaning (Blanco et al., 2009; Lynch et al., 2011, 2012; O'Loughlin et al., 2011, 2012) and housing (Gupta et al., 2007; Hickey et al., 2003a). Gene expression of the potent neutrophil chemokine, CXCL8, was found to be up-regulated following transport (20-fold increase) (Gupta et al., 2007), castration (2-fold increase) (Pang et al., 2009) and weaning (2-fold increase) (O'Loughlin et al., 2011) and may account for distributional alterations in circulating neutrophils, serving to increase immune

\footnotetext{
* Corresponding author. Tel.: +353 469061 100; fax: +353 469026154 .

E-mail address: bernadette.earley@teagasc.ie (B. Earley).
}

surveillance (Jones and Allison, 2007). Stress is reported to induce a response in a number of acute phase proteins (APP), including haptoglobin and serum amyloid A (SAA), with increased concentrations of APP demonstrated in calves following abrupt weaning (Hickey et al., 2003b; Martins et al., 2012) and housing (Alsemgeest et al., 1995). Stress associated with weaning has been linked to immunosuppression and greater incidences of bovine respiratory disease (BRD), mortality and related costs in newly weaned cattle entering feedlots (Hartland et al., 1991). The objective of the present study was to characterise changes in specific blood variables in beef calves subjected to either weaning and separation from their dams, or of housing with their dams.

In the present study we also hypothesised that plasma CXCL8 (formerly known as IL-8) protein levels would increase concurrently with blood neutrophils. The identification and characterisation of novel, specific biomarkers and biomarker profiles of patho-physiological states will be an important step towards the early detection of disease susceptible animals.

\section{Methods}

\subsection{Care and use of animals}

All animal procedures performed in this study were conducted under experimental licence from the Irish Department of Health and Children in accordance with the Cruelty to Animals Act 1876 and the European Communities (Amendment of Cruelty to Animals Act 1876) Regulation 2002 and 2005. 


\subsection{Animal model}

Sixteen clinically healthy, spring-born, single-suckled, Blonde d'Aquitaine sired beef crossbred bull calves were used in this study. Prior to housing, cows and their calves were rotationally grazed on a predominantly perennial ryegrass (Lolium perenne) based sward from early April until housing on the 9th November. Calves were immunised 28 days prior to weaning against bovine respiratory syncytial virus (BRSV) and infectious bovine rhinotracheitis (IBR) virus using Rispoval-3 and Rispoval-IBR vaccines (Pfizer Animal Health, Co. Cork, Ireland), respectively. On the day (d) of weaning (d 0), calves were moved to a handling yard and assigned to one of two treatments: (1) control ( $n=8$; mean weight (s.d.) 292.0 (36.5) kg; mean age (s.d.) 228 (22.1) days), these animals were housed with their dam, (2) weaned ( $n=8$; mean weight (s.d.) 296.5 (59.5) kg; mean age (s.d.) 242 (32.8) days), these animals were abruptly separated from their dam and housed. Pens were equipped with automatic water drinkers and the calves were offered a new diet of grass silage and had free access to concentrates.

\subsection{Rectal temperature measurements}

Rectal body temperature was monitored on $d-4,0,1,2,3,7$ and 14 while calves were waiting in the holding chute just prior to blood sample collection using a digital thermometer (Jorgen Kruuse A/S; model VT-801 BWC Lot No 0701, Marslev, Denmark).

\subsection{Sample collection}

Calves were blood sampled via jugular venipuncture on $d-4$, $0,1,2,3,7$, and 14 relative to weaning ( $\mathrm{d} 0$ ). For this procedure, they were moved gently to a holding pen with a squeeze chute facility and were blood sampled with minimal restraint. Blood sampling was carried out by the same experienced operator on each occasion and the time taken to collect the blood samples was less than 60 s/calf. Blood samples were collected into $1 \times 6 \mathrm{ml}$ spray-dried $\mathrm{K}_{3}$ ethylenediaminetetraacetic acid ( $\mathrm{K}_{3} \mathrm{EDTA}$ ) coated tube (Greiner Vacuette, Cat.-No.: 456038, Cruinn Diagnostics, Ireland) for haematological analysis and $1 \times 9 \mathrm{ml}$ spray-dried lithium heparin coated tubes (Greiner Vacuette Cat.-No.: 455084, Cruinn Diagnostics, Ireland) for cortisol, acute phase protein and CXCL8 analysis.

\subsection{Haematology variables}

Unclotted whole $\mathrm{K}_{3}$ EDTA blood samples were analysed using an ADVIA haematology analyser (AV ADVIA 2120, Bayer Healthcare, Siemens, UK) equipped with software for bovine blood. Total leukocyte, neutrophil, lymphocyte, eosinophil and monocyte percentage, red blood cell (RBC) number, haemoglobin (HGB), mean cell haemoglobin concentration (MCV), mean corpuscular volume (MCV), haematocrit (HCT) percentage and platelet (PLT) number were measured. The neutrophil:lymphocyte $(\mathrm{N}: \mathrm{L})$ ratio was also calculated.

\subsection{Acute phase proteins, cortisol and CXCL8}

Plasma was harvested from the lithium heparin anti-coagulated blood tubes following centrifugation at $1600 \times g$ at $4{ }^{\circ} \mathrm{C}$ for $15 \mathrm{~min}$ and stored at $-80^{\circ} \mathrm{C}$ until analysis. The concentration of plasma haptoglobin was measured using an automatic analyser (spACE, Alfa Wassermann, Inc., West Caldwell, NJ, USA) and commercial assay kit (Tridelta Development Ltd., Wicklow, Ireland) and serum amyloid A using the SAA ELISA kit (Phase Range SAA ELISA kit, Tridelta Development Ltd., Co. Kildare, Ireland). The intra and inter assay CV for haptoglobin were $6.3 \%$ and $4.1 \%$, respectively. SAA had an intra assay CV of $5 \%$. Cortisol was assayed using the Correlate-EIA kit from Assay Designs (Ann Arbor, MI, USA) according to the manufacturer's instructions. Plasma CXCL8 was quantified using the Quantikine IL-8 Immunoassay (R\&D Systems Europe, Ltd., Abingdon, UK) according to the manufacturer's instructions. CXCL8 had an intra and inter assay CV of $7.8 \%$ and $11.6 \%$, respectively.

\subsection{Statistical analysis}

Haematological, acute phase protein, CXCL8 and cortisol data were tested for normality using PROC UNIVARIATE and the ShapiroWilk test and, values that were not normally distributed were log transformed prior to statistical analyses. Haematological, physiological and rectal temperature data were analysed as repeated measures using the PROC MIXED procedure of SAS (Version 9.1, SAS Institute, Cary, NC). The first sample ( -4 ; sample 1) was used as the baseline covariate in the statistical analysis of the data. Animal was the experimental unit and was specified as a repeated measures effect, and the dependence within animal was modelled using an unstructured covariance structure. Data subject to transformation were used to calculate $P$-values. The corresponding least squares means (Lsmeans) and SE of the non-transformed data are presented to facilitate interpretation of results. Differences between treatments were determined using the Tukey-Kramer test for multiple comparisons. Lsmeans were considered significantly different at the $P<0.05$ probability level.

\section{Results}

\subsection{Rectal body temperature}

There was no treatment $\times$ sampling time interaction $(P>0.05)$ for rectal body temperature. Rectal temperature increased $(P<0.01)$ in both control and weaned calves (Table 1). Rectal temperature remained elevated from baseline to $\mathrm{d} 7$ and was greater overall in weaned calves compared to control calves $(P<0.03)$.

Table 1

Effect of weaning induced stress at housing on rectal body temperature $\left({ }^{\circ} \mathrm{C}\right)$ in weaned beef calves. The values are expressed as least squares means $($ Lsmeans) \pm s.e.

\begin{tabular}{|c|c|c|c|c|c|c|c|c|c|c|}
\hline \multirow[t]{2}{*}{ Variable } & & \multicolumn{6}{|c|}{ Days post weaning } & \multicolumn{3}{|c|}{$P$-values } \\
\hline & & 0 & 1 & 2 & 3 & 7 & 14 & $\mathrm{~T}$ & $S$ & $\mathrm{~T} \times \mathrm{S}$ \\
\hline \multirow[t]{2}{*}{ Rectal body temperature } & $\mathrm{C}$ & $38.0 \pm 0.21$ & $38.8^{\mathrm{b}} \pm 0.21$ & $38.7^{\mathrm{b}, \mathrm{x}} \pm 0.07$ & $38.8^{\mathrm{b}} \pm 0.12$ & $38.6^{b} \pm 0.09$ & $38.7^{a} \pm 0.11$ & * & * & NS \\
\hline & W & $38.0 \pm 0.21$ & $38.8^{\mathrm{b}} \pm 0.21$ & $38.7^{\mathrm{b}, \mathrm{x}} \pm 0.07$ & $38.8^{\mathrm{b}} \pm 0.12$ & $38.6^{\mathrm{b}} \pm 0.09$ & $38.7^{a} \pm 0.11$ & & & \\
\hline
\end{tabular}

$\mathrm{T}$, treatment; $\mathrm{S}$, sampling time; $\mathrm{T} \times \mathrm{S}$, treatment $\times$ sampling time interaction; NS, not significant $(P>0.05)$.

a,b,c Within rows, Lsmeans differ from pre-weaning baseline by $P<0.05, P<0.01$ and $P<0.001$, respectively.

$\mathrm{x}, \mathrm{y}$ Between rows, Lsmeans differ by $P<0.05$.

* $P<0.05,{ }^{* *} P<0.01,{ }^{* * *} P<0.001$. 
Table 2

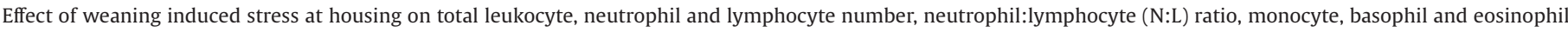
numbers in weaned beef calves. The values are expressed as least squares means (Lsmeans) \pm s.e.

\begin{tabular}{|c|c|c|c|c|c|c|c|c|c|c|}
\hline \multirow[t]{2}{*}{ Variable } & & \multicolumn{6}{|c|}{ Days post weaning } & \multicolumn{3}{|c|}{$P$-values } \\
\hline & & 0 & 1 & 2 & 3 & 7 & 14 & $\mathrm{~T}$ & $S$ & $\mathrm{~T} \times \mathrm{S}$ \\
\hline \multirow[t]{2}{*}{ Total leukocytes $\left(\times 10^{3}\right.$ cells $\left./ \mu \mathrm{l}\right)$} & $\mathrm{C}$ & $8.7 \pm 0.79$ & $7.9^{x} \pm 0.49$ & $8.6^{x} \pm 0.52$ & $10.8^{\mathrm{a}} \pm 0.67$ & $8.6 \pm 0.72$ & $8.3 \pm 0.50$ & NS & $* * *$ & $* *$ \\
\hline & W & $10.1 \pm 0.79$ & $9.6^{y} \pm 0.49$ & $10.5^{y} \pm 0.52$ & $11.2 \pm 0.67$ & $9.7 \pm 0.72$ & $8.2 \pm 0.50$ & & & \\
\hline \multirow[t]{2}{*}{ Neutrophils $\left(\times 10^{3}\right.$ cells $\left./ \mu \mathrm{l}\right)$} & $\mathrm{C}$ & $2.6 \pm 0.31$ & $2.1^{\mathrm{x}} \pm 0.24$ & $2.5 \pm 0.36$ & $3.9^{\mathrm{a}} \pm 0.56$ & $2.5 \pm 0.41$ & $2.1 \pm 0.24$ & NS & NS & $*$ \\
\hline & W & $2.3 \pm 0.31$ & $2.9^{\mathrm{a}, \mathrm{y}} \pm 0.24$ & $3.4^{c} \pm 0.36$ & $4.0^{\mathrm{b}} \pm 0.56$ & $2.7 \pm 0.41$ & $2.5 \pm 0.24$ & & & \\
\hline \multirow{2}{*}{ Lymphocytes $\left(\times 10^{3}\right.$ cells $\left./ \mu \mathrm{l}\right)$} & $\mathrm{C}$ & $6.5 \pm 0.47$ & $6.1 \pm 0.36$ & $6.7 \pm 0.37$ & $6.9 \pm 0.39$ & $6.2 \pm 0.35$ & $5.9 \pm 0.30$ & NS & NS & NS \\
\hline & W & $7.0 \pm 0.47$ & $6.4 \pm 0.36$ & $6.4 \pm 0.37$ & $7.1 \pm 0.39$ & $6.8 \pm 0.35$ & $5.8^{a} \pm 0.30$ & & & \\
\hline \multirow[t]{2}{*}{$\mathrm{N}:$ L ratio } & $\mathrm{C}$ & $0.39 \pm 0.041$ & $0.36 \pm 0.033$ & $0.39 \pm 0.040$ & $0.62^{b} \pm 0.096$ & $0.42 \pm 0.044$ & $0.35 \pm 0.046$ & NS & $*$ & $* * *$ \\
\hline & W & $0.36 \pm 0.041$ & $0.46^{b} \pm 0.033$ & $0.49^{c} \pm 0.040$ & $0.55^{\mathrm{b}} \pm 0.096$ & $0.39 \pm 0.044$ & $0.46^{a} \pm 0.046$ & & & \\
\hline \multirow[t]{2}{*}{ Monocytes $\left(\times 10^{3}\right.$ cells $\left./ \mu \mathrm{l}\right)$} & $\mathrm{C}$ & $0.52 \pm 0.079$ & $0.53 \pm 0.051$ & $0.43 \pm 0.035$ & $0.58 \pm 0.044$ & $0.51 \pm 0.081$ & $0.55 \pm 0.049$ & NS & NS & NS \\
\hline & W & $0.46 \pm 0.079$ & $0.42 \pm 0.051$ & $0.39 \pm 0.035$ & $0.51 \pm 0.044$ & $0.48 \pm 0.081$ & $0.42 \pm 0.049$ & & & \\
\hline \multirow[t]{2}{*}{ Basophils $\left(\times 10^{3}\right.$ cells $\left./ \mu \mathrm{l}\right)$} & $\mathrm{C}$ & $0.11 \pm 0.015$ & $0.11 \pm 0.011$ & $0.12 \pm 0.012$ & $0.14 \pm 0.013$ & $0.13 \pm 0.012$ & $0.11 \pm 0.011$ & NS & NS & NS \\
\hline & W & $0.13 \pm 0.015$ & $0.10 \pm 0.011$ & $0.11 \pm 0.012$ & $0.12 \pm 0.013$ & $0.12 \pm 0.012$ & $0.10 \pm 0.011$ & & & \\
\hline \multirow[t]{2}{*}{ Eosinophils $\left(\times 10^{3}\right.$ cells $\left./ \mu \mathrm{l}\right)$} & $\mathrm{C}$ & $0.16 \pm 0.072$ & $0.15 \pm 0.074$ & $0.18^{x} \pm 0.107$ & $0.16 \pm 0.113$ & $0.16 \pm 0.055$ & $0.15 \pm 0.038$ & $*$ & NS & NS \\
\hline & W & $0.33 \pm 0.072$ & $0.32 \pm 0.074$ & $0.49^{\mathrm{y}} \pm 0.107$ & $0.47 \pm 0.113$ & $0.26 \pm 0.055$ & $0.17 \pm 0.038$ & & & \\
\hline
\end{tabular}

$\mathrm{T}$, treatment; $\mathrm{S}$, sampling time; $\mathrm{T} \times \mathrm{S}$, treatment $\times$ sampling time interaction; NS, not significant $(P>0.05)$.

* $P<0.05$, ** $P<0.01$, *** $P<0.001$.

a,b,c Within rows, Lsmeans differ from pre-weaning baseline by $P<0.05, P<0.01$ and $P<0.001$, respectively.

$x, y$ Between rows, Lsmeans differ by $P<0.05$.

\subsection{Haematological responses}

There was no effect $(P>0.05)$ of treatment, sampling time or their interaction on lymphocyte, monocyte, basophil or eosinophil number (Table 2). For total leukocyte number, there was a treatment $\times$ sampling time interaction $(P<0.01)$ whereby total leukocyte number was greater $(P<0.05)$ in weaned calves than control calves on $\mathrm{d} 1$ and $\mathrm{d} 2$. Similarly, there was a treatment $\times$ sampling time interaction for neutrophil number $(P<0.05)$ and $N$ : L ratio $(P<0.001)$. In weaned calves, neutrophils increased on $\mathrm{d} 1(P<0.05), \mathrm{d} 2(P<0.001)$ and $\mathrm{d} 3(P<0.01)$ relative to baseline, resulting in greater levels compared to control calves on $\mathrm{d} 1$, whereas in control calves, neutrophil number did not increase $(P>0.05)$ from baseline until d $3(P<0.05)$ (Fig. 1). As a reflection of alterations to total neutrophil number, the $\mathrm{N}$ : L ratio was elevated $(P<0.01)$ from baseline in weaned animals at sampling on d 1, d 2 and d 3, whereas an increase in control calves was not evident until d 3. Eosinophil number was greater $(P<0.05)$ in weaned calves than control calves on $\mathrm{d} 2$.

Platelet number increased from baseline in control calves on $\mathrm{d}$ $3(P<0.01), \mathrm{d} 7(P<0.001)$ and $\mathrm{d} 14(P<0.01)$ (Table 3$)$. There was

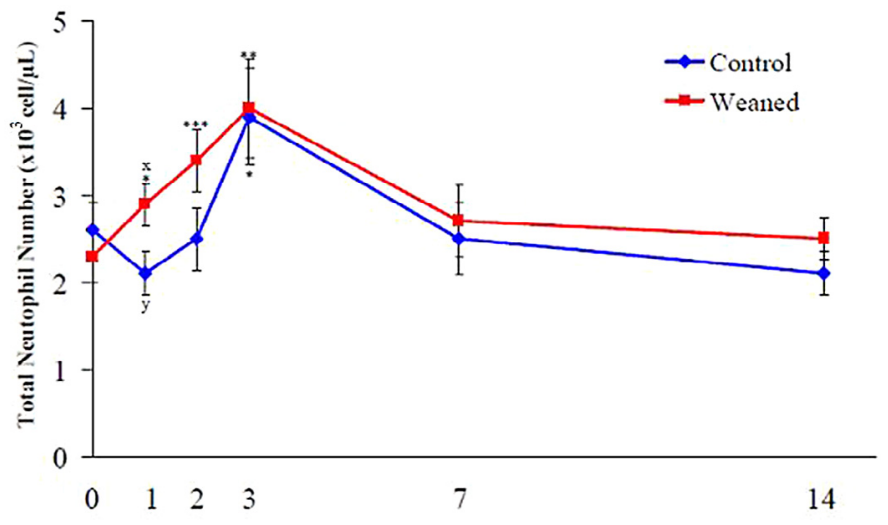

Day relative to weaning (D 0$)$

Fig. 1. The neutrophil response to housing and weaning stress. Total neutrophil number increased immediately following abrupt weaning at housing while there is a delay in a delayed neutrophilia in housed calves on $\mathrm{d} 3$. $^{*} \mathrm{P}<0.05,{ }^{*} \mathrm{P}<0.01$, ${ }^{* * *} P<0.001$. Lsmeans differ relative to baseline ( $\left.\mathrm{d} 0\right)$. ${ }^{\mathrm{X}, \mathrm{Y}}$ Lsmeans differ between treatments $(P<0.05)$ a treatment $\times$ sampling time interaction $(P<0.05)$ for mean platelet volume (MPV) whereby MPV was greater $(P<0.05)$ in control calves on $\mathrm{d} 7$ than weaned calves and the inverse was true on $\mathrm{d} 14$ (Table 3$)$. RBC number was less than baseline $(P<0.01)$ on $\mathrm{d} 1$ and d 14 in weaned calves and on d 7 and d 14 in control calves. Haemoglobin concentration (HGB) followed a similar trend and was less than baseline $(P<0.01)$ in weaned calves on $\mathrm{d} 1, \mathrm{~d} 7$ and $\mathrm{d} 14$, and was less than baseline $(P<0.05)$ in control calves on $\mathrm{d} 14$. Haematocrit (HCT) \% also decreased from baseline on d 1 and d 14 in weaned calves $(P<0.01)$ and on d $1, \mathrm{~d} 7$ and d 14 in control calves $(P<0.05)$. Likewise, mean corpuscular volume (MCV) decreased in weaned calves $(P<0.001)$ on $\mathrm{d} 1$ and $\mathrm{d} 14$ and in control calves $(P<0.05)$ on $\mathrm{d} 1$ and $\mathrm{d} 7$.

\subsection{Inflammatory responses}

There was no effect of treatment or treatment $\times$ sampling time interaction $(P>0.05)$ for serum amyloid A (SAA) (Table 4$)$, whereas there was a treatment $\times$ time interaction for haptoglobin. Haptoglobin was significantly elevated $(P<0.01)$ from baseline in weaned calves on $\mathrm{d} 2$ and $\mathrm{d} 7$, with no alterations in control calves. A treatment $\times$ sampling time $(P<0.01)$ interaction was identified for circulating plasma CXCL8 concentrations whereby CXCL8 concentration increased $(P<0.001)$ in both treatments following either housing or weaning at housing but was greater $(P<0.05)$ in control calves than weaned calves on $\mathrm{d} 1$ and $\mathrm{d} 3$ (Fig. 2).

\subsection{Steroid hormone response}

There was a treatment $\times$ sampling time interaction $(P<0.05)$ for cortisol whereby circulating cortisol concentration increased from baseline in weaned animals on $\mathrm{d} 2(P<0.05)$ and $\mathrm{d} 3(P<0.01)$ and remained elevated throughout the rest of the study $(P<0.05)$, whereas, this only occurred in control calves on $\mathrm{d} 7$ (Table 5).

\section{Discussion}

Weaning typically combines a number of physical and psychological stressors which have the potential to alter the immune state and increase susceptibility to bovine respiratory disease. Stress occurs when an animal's homeostasis is disrupted, the stress response consists of a set of physiological mechanisms designed to return to homeostasis. Thus the systemic reaction to a stressor encompasses a 
Table 3

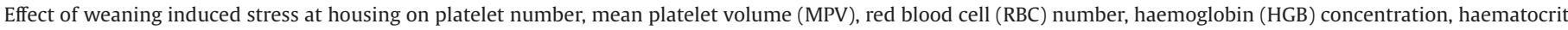

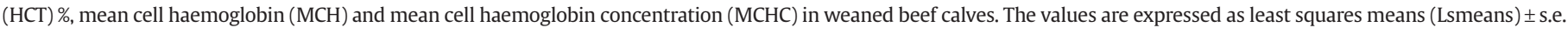

\begin{tabular}{|c|c|c|c|c|c|c|c|c|c|c|}
\hline \multirow[t]{2}{*}{ Variable } & & \multicolumn{6}{|c|}{ Days post weaning } & \multicolumn{3}{|c|}{$P$-values } \\
\hline & & 0 & 1 & 2 & 3 & 7 & 14 & $\mathrm{~T}$ & $\mathrm{~S}$ & $\mathrm{~T} \times \mathrm{S}$ \\
\hline \multirow[t]{2}{*}{ Platelets $\left(\times 10^{3}\right.$ cells $\left./ \mu \mathrm{l}\right)$} & $\mathrm{C}$ & $421.4 \pm 64.1$ & $528.4 \pm 60.3$ & $609.5 \pm 76.1$ & $713.1^{\mathrm{b}} \pm 27.0$ & $840.9^{c} \pm 48.0$ & $731.3^{\mathrm{b}} \pm 50.1$ & NS & $*$ & NS \\
\hline & W & $540.6 \pm 64.1$ & $653.1 \pm 60.3$ & $529.2 \pm 76.1$ & $648.4 \pm 27.0$ & $674.3 \pm 48.0$ & $618.1 \pm 50.1$ & & & \\
\hline \multirow[t]{2}{*}{ MPV (fL) } & $C$ & $12.5 \pm 1.88$ & $17.7 \pm 2.10$ & $13.3 \pm 1.97$ & $10.6 \pm 1.25$ & $14.3^{x} \pm 1.10$ & $9.7^{x} \pm 1.14$ & NS & $*$ & $*$ \\
\hline & $\mathrm{W}$ & $12.6 \pm 1.88$ & $12.2 \pm 2.10$ & $12.9 \pm 1.97$ & $11.1 \pm 1.25$ & $10.5^{y} \pm 1.10$ & $13.6^{y} \pm 1.14$ & & & \\
\hline \multirow[t]{2}{*}{$\mathrm{RBC}\left(\times 10^{6}\right.$ cells $\left./ \mu \mathrm{l}\right)$} & $\mathrm{C}$ & $11.4 \pm 0.21$ & $10.9 \pm 0.14$ & $11.1 \pm 0.23$ & $10.9 \pm 0.26$ & $10.7^{b} \pm 0.25$ & $10.7^{a} \pm 0.30$ & NS & $*$ & NS \\
\hline & W & $11.5 \pm 0.21$ & $10.8^{\mathrm{b}} \pm 0.14$ & $11.3 \pm 0.23$ & $11.2 \pm 0.26$ & $11.1 \pm 0.25$ & $10.1^{c} \pm 0.30$ & & & \\
\hline \multirow[t]{2}{*}{$\mathrm{HGB}(\mathrm{g} / \mathrm{dl})$} & $\mathrm{C}$ & $13.3 \pm 0.28$ & $12.9 \pm 0.17$ & $13.1 \pm 0.24$ & $12.9 \pm 0.25$ & $12.9 \pm 0.22$ & $12.8^{a} \pm 0.34$ & NS & $*$ & NS \\
\hline & W & $13.3 \pm 0.28$ & $12.5^{\mathrm{b}} \pm 0.17$ & $13.1 \pm 0.24$ & $12.9 \pm 0.25$ & $12.6^{\mathrm{b}} \pm 0.22$ & $11.8^{c} \pm 0.34$ & & & \\
\hline \multirow[t]{2}{*}{ HCT (\%) } & $C$ & $35.7 \pm 0.75$ & $33.7^{\mathrm{a}} \pm 0.44$ & $34.6 \pm 0.82$ & $34.6 \pm 0.84$ & $33.8^{a} \pm 0.64$ & $33.7^{\mathrm{a}} \pm 1.03$ & NS & $*$ & NS \\
\hline & W & $35.8 \pm 0.75$ & $33.1^{\mathrm{b}} \pm 0.44$ & $34.8 \pm 0.82$ & $34.6 \pm 0.84$ & $34.4 \pm 0.64$ & $30.9^{c} \pm 1.03$ & & & \\
\hline \multirow[t]{2}{*}{$\operatorname{MCV}(\mathrm{fL})$} & $C$ & $31.3 \pm 0.13$ & $30.8^{\mathrm{b}} \pm 0.09$ & $31.1 \pm 0.17$ & $31.3 \pm 0.14$ & $31.5^{\mathrm{a}} \pm 0.15$ & $31.3 \pm 0.15$ & NS & $* * *$ & $* *$ \\
\hline & W & $31.6 \pm 0.13$ & $30.9^{c} \pm 0.09$ & $31.4 \pm 0.17$ & $31.5 \pm 0.14$ & $31.6 \pm 0.15$ & $30.9^{c} \pm 0.15$ & & & \\
\hline
\end{tabular}

T, treatment; $\mathrm{S}$, sampling time; $\mathrm{T} \times \mathrm{S}$, treatment $\times$ sampling time interaction; NS, not significant $(P>0.05)$.

* $P<0.05$, ** $P<0.01$, *** $P<0.001$.

a,b,c Within rows, Lsmeans differ from pre-weaning baseline by $P<0.05, P<0.01$ and $P<0.001$, respectively.

x,y Between rows, Lsmeans differ by $P<0.05$.

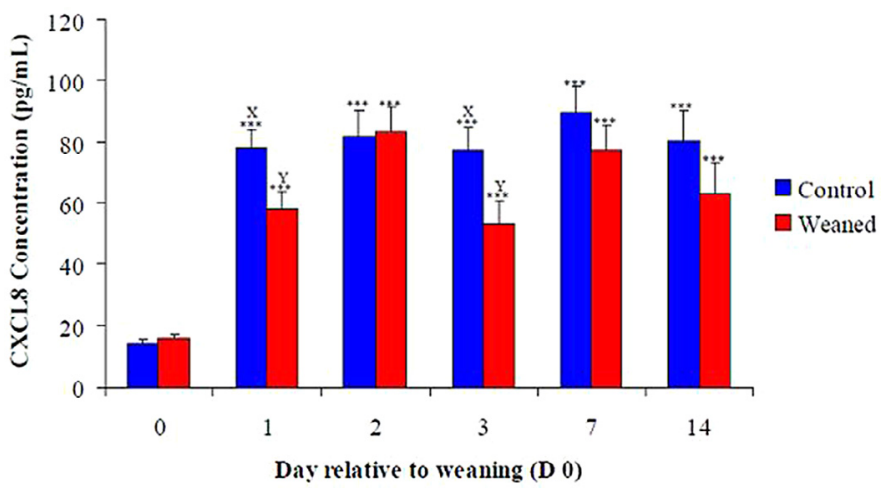

Fig. 2. The circulating plasma CXCL8 response to housing and weaning stress. Following either housing or weaning, CXCL8 concentration increased significantly and remained elevated at sampling throughout the course of the study. ${ }^{*} P<0.05,{ }^{* *} P<0.01$, ${ }^{* * *} P<0.001$. Lsmeans differ relative to baseline $(\mathrm{d} 0)$. ${ }^{\mathrm{X}, \mathrm{Y}}$ Lsmeans differ between treatments $(P<0.05)$. wide range of endocrinological, immunological and inflammatory responses. During periods of stress, a percentage of available nutrients from caloric intake are diverted away from processes such as growth and muscle deposition and have a role in stabilising other physiological processes (i.e. those required for survival, e.g. an immune response) (Elsasser et al., 1997, 2008). Furthermore, intake and appetite are suppressed during stressful events (Haddad et al., 2002) with intake of nutrients by stressed livestock often compromised and below that normally consumed by unstressed animals (Duff and Galyean, 2007). Weaning under modern cattle production systems may be described as a multi-factorial stressor as it incorporates nutritional, physical and psychological elements (Weary et al., 2008). Calves are often subjected to an array of husbandry practices which may compound their stress at the time of weaning. Additional husbandry practices can include frequent handling and contact with humans, mixing with unfamiliar cattle, movement to new environments whether it be indoor housing or unfamiliar paddocks, switching to different, entirely solid diets, transportation and marketing. Some cattle may also undergo additional processing such

Table 4

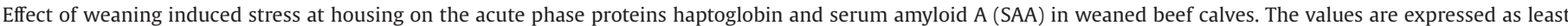
squares means (Lsmeans) \pm s.e.

\begin{tabular}{|c|c|c|c|c|c|c|c|c|c|c|}
\hline \multirow[t]{2}{*}{ Variable } & & \multicolumn{6}{|c|}{ Days post weaning } & \multicolumn{3}{|c|}{$P$-values } \\
\hline & & 0 & 1 & 2 & 3 & 7 & 14 & $\mathrm{~T}$ & $\mathrm{~S}$ & $\mathrm{~T} \times \mathrm{S}$ \\
\hline \multirow[t]{2}{*}{ Haptoglobin (mg/ml) } & $\mathrm{C}$ & $0.57 \pm 0.09$ & $0.52 \pm 0.043$ & $0.66 \pm 0.072$ & $0.79 \pm 0.104$ & $0.74 \pm 0.115$ & $0.67 \pm 0.038$ & NS & $* *$ & $*$ \\
\hline & W & $0.54 \pm 0.09$ & $0.46 \pm 0.043$ & $0.72^{\mathrm{b}} \pm 0.072$ & $0.64 \pm 0.104$ & $0.78^{a} \pm 0.115$ & $0.64 \pm 0.038$ & & & \\
\hline \multirow[t]{2}{*}{$\mathrm{SAA}(\mu \mathrm{g} / \mathrm{ml})$} & $C$ & $104.3 \pm 16.0$ & $101.8 \pm 15.5$ & $98.9 \pm 15.9$ & $116.3 \pm 13.8$ & $53.7^{\mathrm{b}} \pm 16.5$ & $46.4^{\mathrm{a}} \pm 11.2$ & NS & $* *$ & NS \\
\hline & W & $62.1 \pm 17.5$ & $89.4 \pm 16.9$ & $119.5^{\mathrm{a}} \pm 17.4$ & $105.8 \pm 15.0$ & $62.5 \pm 18.1$ & $32.8 \pm 12.3$ & & & \\
\hline
\end{tabular}

$\mathrm{T}$, treatment; $\mathrm{S}$, sampling time; $\mathrm{T} \times \mathrm{S}$, treatment $\times$ sampling time interaction; NS, not significant $(P>0.05)$.

* $P<0.05,{ }^{* *} P<0.01,{ }^{* * *} P<0.001$.

a,b,c Within rows, Lsmeans differ from pre-weaning baseline by $P<0.05, P<0.01$ and $P<0.001$, respectively.

Table 5

Effect of weaning induced stress at housing on circulating serum cortisol concentrations. The values are expressed as least squares means (Lsmeans) \pm s.e.

\begin{tabular}{|c|c|c|c|c|c|c|c|c|c|c|}
\hline \multirow[t]{2}{*}{ Variable } & & \multicolumn{6}{|c|}{ Days post weaning } & \multicolumn{3}{|c|}{$P$-values } \\
\hline & & 0 & 1 & 2 & 3 & 7 & 14 & $\mathrm{~T}$ & $\mathrm{~S}$ & $\mathrm{~T} \times \mathrm{S}$ \\
\hline \multirow[t]{2}{*}{ Cortisol (ng/ml) } & $\mathrm{C}$ & $4.8 \pm 1.09$ & $5.4 \pm 1.13$ & $5.1 \pm 1.07$ & $5.4 \pm 1.05$ & $7.2^{\mathrm{a}} \pm 0.75$ & $3.7 \pm 0.95$ & NS & NS & $*$ \\
\hline & $\mathrm{W}$ & $3.4 \pm 1.09$ & $4.2 \pm 1.13$ & $5.1^{\mathrm{a}} \pm 1.07$ & $5.6^{\mathrm{b}} \pm 1.05$ & $5.2^{\mathrm{a}} \pm 0.75$ & $5.1^{\mathrm{a}} \pm 0.95$ & & & \\
\hline
\end{tabular}

$\mathrm{T}$, treatment; $\mathrm{S}$, sampling time; $\mathrm{T} \times \mathrm{S}$, treatment $\times$ sampling time interaction; NS, not significant $(P>0.05)$.

* $P<0.05,{ }^{* *} P<0.01$, *** $P<0.001$.

a,b,c Within rows, Lsmeans differ from pre-weaning baseline by $P<0.05, P<0.01$ and $P<0.001$, respectively. 
as vaccinations, dehorning and castration. Additionally, because stress can manifest as a variety of interrelated physiological, metabolic, endocrinological, and behavioural processes, which can impair immune defence, the search for biological measures to provide an objective assessment of animal welfare status is warranted. It is thus important to fully characterise the weaning process in order to assess the potential health and animal welfare implications that weaning can have when combined with housing and social reorganisation. This will permit adaptation of herd management practices in order to alleviate stress in livestock and avoid compromising their immune system response.

Of particular importance in evaluating the prolonged effects of weaning stress are the numbers of leukocytes, including neutrophils, lymphocytes, eosinophils, and monocytes in the circulation. In the present study, a number of alterations to the blood leukogram were identified. Weaning and housing have both been previously shown to increase total leukocyte number (Blanco et al., 2009; Hickey et al., 2003b; Lynch et al., 2010) as a result of fluctuations in a number of leukocyte subpopulations, particularly neutrophils. Elevations in endogenous or exogenous glucocorticoids are reported to cause a dramatic shift in the haematological profile of peripheral blood cells resulting in leukocytosis which is marked by neutrophilia and lymphopenia (Burton et al., 2005). In the present study, following abrupt weaning, neutrophil number increased by $43 \%$ at day 3 . This increase is consistent with our previous work where the order of magnitude across five studies was 39\% (s.e. 9.4\%) (Hickey et al., 2003b; Lynch et al., 2010, 2011, 2012; O'Loughlin et al., 2012). These data strongly indicate that neutrophil number is a robust biomarker to detect weaning stress in beef calves.

The delayed increase in neutrophil number in calves housed with their dam indicates that weaning and separation of calves from their dams is more stressful. Similarly, Lynch et al. (2011) reported that deferring housing at the time of weaning resulted in a less marked stress response in beef calves (25\%) compared with the traditional practice of weaning and simultaneous housing indoors at the end of the grazing season (62\%; (Lynch et al., 2010) and 46\% (Lynch et al., 2012) increases, respectively). Compared with abrupt weaning, practices such as progressive weaning or fenceline weaning have reduced the frequency of behavioural distress, heart rate and neutrophil:lymphocyte $(\mathrm{N}: \mathrm{L})$ ratio in calves (Church and Hudson, 1999; Price et al., 2003; Rasby, 2007). More recently, O'Loughlin et al. (2011) reported that beef calves, particularly bulls, had a strong stress response and may benefit from a weaning strategy where they are allowed visual, oral and olfactory contact with the dam but are prevented from suckling for a number of days prior to total separation.

While lymphocytes are generally regarded as being an adjunct to neutrophils in the detection of the bovine stress response, although not significant in the present study, there was a (9\%) numerical decrease in the lymphocyte number following weaning. This is consistent with previous studies with decreases ranging from $6 \%$ (O'Loughlin et al., 2011) to 9\% (Hickey et al., 2003b), in contrast to a significant decrease, on average $27 \%$ (s.e. $6.6 \%$ ), in a number of other studies that found lymphocyte number decreased in response to weaning and returning to baseline levels within 7 days (Lynch et al., 2010, 2012; O'Loughlin et al., 2012). Another useful measure of the sustained effect of stress is the N:L ratio, which increased due to weaning and weaning at housing. Coupled with the reported neutrophilia, the N:L ratio increased from baseline on the first 3 days following weaning, while also increasing in the control animals on $\mathrm{d} 3$.

The increase in neutrophil number identified in weaned calves in this study and our previous work suggests that weaning stress is transient such that neutrophil numbers return to baseline within 3-7 days. However, in the current study, elevated concentrations of plasma CXCL8 indicate that a stress response was still evident at day 14.

CXCL8 is an important inflammatory mediator, predominantly responsible for the chemotaxis of neutrophils, although it also functions in T cell migration (Elenkov et al., 2005; Keller et al., 2005). In the present study, CXCL8 increased in control and weaned calves, indicating a non-specific response to stress. That is to say, the change from a pasture to a housing environment was sufficient to increase CXCL8 concentrations, and the additional stressor of weaning did not increase the magnitude of CXCL8. In the short term, the increased concentration of CXCL8 likely served to enhance neutrophil migration and surveillance of the tissues most at risk from infection. However, prolonged exposure to inflammatory cytokines can paradoxically result in deleterious effects, producing severe tissue damage, particularly in soft tissues such as the lung (Buckham-Sporer et al., 2007; Eruslanov et al., 2005; Mitchell et al., 2008) and thus increasing the susceptibility of the calves to disease. More recently, O'Loughlin et al. (2011) reported that the expression of proinflammatory cytokine genes in leukocytes, including CXCL8, were upregulated up to 7 days in calves following weaning and housing. The increased concentrations of CXCL8 in control and weaned calves on day 1 suggest that CXCL8 is a more sensitive marker than neutrophil number.

Although concentrations of cortisol were higher in weaned calves from day 2 to 14 relative to baseline compared to an elevation at day 7 in control calves, caution is required in the interpretation of these findings owing to its sensitivity to frequency and time of sampling, and animal handling. Nevertheless, in previous studies, Hickey et al. (2003b) reported that weaning resulted in elevated concentrations of cortisol up to $7 \mathrm{~d}$ post-weaning.

Acute phase proteins are frequently selected as biomarkers of stress in cattle (Lynch et al., 2010, 2012; O'Loughlin et al., 2012). However, in accord with our previous findings Hickey et al. (2003b); Lynch et al., 2010, 2011, 2012; O'Loughlin et al., 2011, 2012), in the present study there was inconsistent effects to the stress of weaning in the acute phase proteins, haptoglobin and SAA. This indicates that they are an unreliable biomarker of stress.

Findings pertaining to the effects of weaning acute phase protein response in beef calves are not consistent. Although some studies have shown that this response is activated through the measurement of fibrinogen, ceruloplasmin and SAA (Arthington et al., 2003, 2008; Blanco et al., 2009; Carroll et al., 2009), others have reported that concentrations of fibrinogen and haptoglobin are not affected by weaning (Hickey et al., 2003b).

Weaning in combination with housing of beef calves is often associated with respiratory disease. In this respect a number of other blood variables, in conjunction with rectal body temperatures, were examined as indicators of calf health. In the present study, no change was found in monocyte, basophil, eosinophil, platelet, red blood cell numbers, haematocrit \% or plasma concentrations of haemoglobin, however, a number of mild fluctuations occurred within these variables, but all of these were within the normal physiological range (Jones and Allison, 2007). Calves in the present study did not succumb to respiratory disease, or any other clinical infections or related health problems, based on rectal temperature, physical examination and assessment of appropriate blood variables. This was due in part to the vaccination program employed, coupled with the good husbandry management procedures and prevailing environmental conditions.

Weaning is a multifaceted stressor, with calves that were weaned showing a stronger physiological stress response than control calves that remained with their dams. This study confirmed that neutrophil number is a robust biomarker of stress and additionally that plasma CXCL8 is a sensitive indicator of stress in weaned and control calves. In future studies, these two biomarkers should be central to the characterisation of stress responses. 


\section{Acknowledgements}

The authors gratefully acknowledge Eddie Mulligan and Liam McWeeney for their skilled technical assistance, the farm staff at Teagasc, Grange Livestock Systems Research Department for the Care and Management of the Animals, and Joe Larkin and Margaret Murray for blood analysis. This study was funded by a Teagasc Walsh Fellowship to Aran O'Loughlin (Research Management Information System (RMIS) project number: 5742).

\section{References}

Alsemgeest, S., Lambooy, I., Wierenga, H., Dieleman, S., Meerkerk, B., Van Ederen, A., et al., 1995. Influence of physical stress on the plasma concentration of serum amyloid-a (SAA) and haptoglobin (hp) in calves. The Veterinary Quarterly 17, 9-12.

Arthington, D.J., Qui, X., Cooke, R.F., Vendramini, J.M.B., Araujo, D.B., Chase, C.C., Jr., et al., 2008. Effects of preshipping management on measures of stress and performance of beef steers during feedlot receiving. Journal of Animal Science 86, 2016-2023.

Arthington, J.D., Eicher, S.D., Kunkle, W.E., Martin, F.G., 2003. Effect of transportation and commingling on the acute-phase protein response, growth, and feed intake of newly weaned beef calves. Journal of Animal Science 81, 1120-1125.

Blanco, M., Casasús, I., Palacio, J., 2009. Effect of age at weaning on the physiological stress response and temperament of two beef cattle breeds. Animal 3, 108-117.

Buckham-Sporer, K.R., Burton, J.L., Earley, B., Crowe, M.A., 2007. Transportation stress in young bulls alters expression of neutrophil genes important for the regulation of apoptosis, tissue remodeling, margination, and anti-bacterial function. Veterinary Immunology and Immunopathology 118, 19-29.

Burton, J.L., Madsen, S.A., Chang, L.C., Weber, P.S.D., Buckham, K.R., van Dorp, R., et al., 2005. Gene expression signatures in neutrophils exposed to glucocorticoids: a new paradigm to help explain "neutrophil dysfunction" in parturient dairy cows. Veterinary Immunology and Immunopathology 105, 197-219.

Carroll, J.A., Arthington, J.D., Chase, C.C., Jr., 2009. Early weaning alters the acute-phase reaction to endotoxin challenge in beef calves. Journal of Animal Science 87, 4167-4172.

Church, J.S., Hudson, R.J., 1999. Comparison of the stress of abrupt and interval weaning of farmed wapiti deer (Cervus elaphus). Small Ruminant Research 32, 119-124.

Duff, G.C., Galyean, M.L., 2007. Recent advances in management of highly stressed, newly received feedlot cattle. Journal of Animal Science 85, 823-840.

Elenkov, I.J., Iezzoni, D.G., Daly, A., Harris, A.G., Chrousos, G.P., 2005. Cytokine dysregulation, inflammation and well-being. Neuroimmunomodulation 12 , 255-269.

Elsasser, T.H., Kahl, S., Steele, N.C., Rumsey, T.S., 1997. Nutritional modulation of somatotrophic axis-cytokine relationships in cattle: a brief review. Comparative Biochemistry and Physiology - Part A: Molecular \& Integrative Physiology 116, 209-221.

Elsasser, T.H., Caperna, T.J., Li, C.-J., Kahl, S., Sartin, J.L., 2008. Critical control points in the impact of proinflammatory immune response on growth and metabolism. Journal of Animal Science 86, E105-E125.

Enriquez, D., Hotzel, M., Ungerfeld, R., 2011. Minimising the stress of weaning of beef calves: a review. Acta Veterinaria Scandinavica 53, 28.

Eruslanov, E.B., Lyadova, I.V., Kondratieva, T.K., Majorov, K.B., Scheglov, I.V., Orlova, M.O., et al., 2005. Neutrophil responses to Mycobacterium tuberculosis infection in genetically susceptible and resistant mice. Infection and Immunology 73 , 1744-1753.

Gupta, S., Earley, B., Crowe, M.A., 2007. Pituitary, adrenal, immune and performance responses of mature Holstein $\times$ Friesian bulls housed on slatted floors at various space allowances. The Veterinary Journal 173, 594-604.

Haddad, J.J., Saadé, N.E., Safieh-Garabedian, B., 2002. Cytokines and neuro-immuneendocrine interactions: a role for the hypothalamic-pituitary-adrenal revolving axis. Journal of Neuroimmunology 133, 1-19.

Hartland, R.J., Jim, G.K., Guichon, P.T., Townsend, H.G.G., Janzen, E.D., 1991. Efficacy of parental antibiotics for disease prophylaxis in feedlot cattle. Canadian Veterinary Journal 32, 163-168.

Hickey, M.C., Earley, B., Fisher, A.D., 2003a. The effect of floor type and space allowance on welfare indicators of finishing steers. Irish Journal of Agriculture and Food Research 42, 89-100.

Hickey, M.C., Drennan, M., Earley, B., 2003b. The effect of abrupt weaning of suckler calves on the plasma concentrations of cortisol, catecholamines, leukocytes, acute-phase proteins and in vitro interferon-gamma production. Journal of Animal Science 81, 2847-2855.

Jones, M.L., Allison, R.W., 2007. Evaluation of the ruminant complete blood cell count. Veterinary Clinic of North America Food Animal Practice 23, $377-$ 402.

Keller, M., Spanou, Z., Schaerli, P., Britschgi, M., Yawalkar, N., Seitz, M., et al., 2005. T-cell-regulated neutrophilic inflammation in autoinflammatory diseases. The Journal of Immunology 175, 7678-7686.

Lynch, E.M., Earley, B., McGee, M., Doyle, S., 2010. Effect of abrupt weaning at housing on leukocyte distribution, functional activity of neutrophils, and acute phase protein response of beef calves. BMC Veterinary Research 6, 39.

Lynch, E.M., Earley, B., McGee, M., Doyle, S., 2011. Effect of post-weaning management practices on physiological and immunological responses of weaned beef calves. Irish Journal of Agricultural and Food Research 50 (2), 161-174.

Lynch, E.M., McGee, M., Doyle, S., Earley, B., 2012. Effect of pre-weaning concentrate supplementation on peripheral distribution of leukocytes, functional activity of neutrophils, acute phase protein and behavioural responses of abruptly weaned and housed beef calves. BMC Veterinary Research 8, 1.

Martins, P.G.M.A., Arthington, J.D., Cooke, R.F., Lamb, C.G., Araújo, D.B., Torres, C.A.A., et al., 2012. Evaluation of beef cow and calf separation systems to improve reproductive performance of first-calf cows. Livestock Science 150 (1-3), 7479.

Mitchell, G.B., Clark, M.E., Siwicky, M., Caswell, J.L., 2008. Stress alters the cellular and proteomic compartments of bovine bronchoalveolar lavage fluid. Veterinary Immunology and Immunopathology 125, 111-125.

O'Loughlin, A., McGee, M., Waters, S., Doyle, S., Earley, B., 2011. Examination of the bovine leukocyte environment using immunogenetic biomarkers to assess immunocompetence following exposure to weaning stress. BMC Veterinary Research 7, 45.

O’Loughlin, A., Lynn, D.J., McGee, M., Doyle, S., McCabe, M., Earley, B., 2012. Transcriptomic analysis of the stress response to weaning at housing in bovine leukocytes using RNA-seq technology. BMC Genomics 13, 250.

Pang, W., Earley, B., Sweeney, T., Gath, V., Crowe, M.A., 2009. Temporal patterns of inflammatory gene expression in local tissues after banding or Burdizzo castration in cattle. BMC Veterinary Research 5, 36.

Price, E.O., Harris, J.E., Borgwardt, R.E., Sween, M.L., Connor, J.M., 2003. Fenceline contact of beef calves with their dams at weaning reduces the negative effects of separation on behaviour and growth rate. Journal of Animal Science 81, $116-121$.

Rasby, R., 2007. Early weaning beef calves. The Veterinary Clinics of North America. Food Animal Practice 23, 29-40.

Weary, D.M., Jasper, J., Hötzel, M.J., 2008. Understanding weaning distress. Applied Animal Behaviour Science 110, 24-41. 